\title{
Do Farmer Professional Cooperatives Improve Technical Efficiency and Income? Evidence from Small Vegetable Farms in China
}

\author{
Ying Dong ${ }^{1} \mathbb{D}$, Yueying $\mathrm{Mu}^{2, *}$ and David Abler ${ }^{3, * *}$ \\ ${ }^{1}$ College of Economics and Management, South China Agricultural University, Guangzhou, China, ${ }^{2}$ College of Economics and \\ Management, China Agricultural University, Beijing, China and ${ }^{3}$ Department of Agricultural Economics, Sociology, and \\ Education, The Pennsylvania State University, University Park, Pennsylvania, USA \\ ${ }^{\star}$ Corresponding author. Email: yueyingmu@cau.edu.cn \\ ${ }^{*}$ Corresponding author. Email: dave@bythenumbers.info
}

\begin{abstract}
China's small-scale agricultural producers face many challenges to increasing productivity and efficiency. In recent years, the Chinese government has provided support for farmer professional cooperatives (FPCs) to connect small farms with upstream and downstream processes in the food supply chain. This study combines propensity score matching and sample selection-corrected stochastic production frontier analysis to estimate the impacts of FPC participation by greenhouse vegetable producers on technical efficiency and income. Results indicate that FPCs help participants improve returns to scale and marginal returns to land and labor, increase technical efficiency, and obtain $¥ 4,460$ (18\%) greater income per greenhouse than nonparticipants.
\end{abstract}

Keywords: Farmer professional cooperatives; greenhouse vegetables; metafrontier; propensity score matching; selection bias; technical efficiency

JEL Classifications: Q12; Q16

\section{Introduction}

China's small-scale agricultural producers face many challenges to increasing productivity and efficiency. The average farm size in China is only about 0.6 ha, and among vegetable producers, the average size is even smaller-about 0.03 ha in northern China (Wang et al., 2009). Adopting new production techniques can entail high learning and adjustment costs, compounded for small farmers in China by a lack of agricultural extension agents to disseminate information on new techniques (Hu et al., 2012; Jin et al., 2010). Most small farm households cannot access modern marketing channels because of an inability to meet the required food safety and quality standards (Jia, Huang, and $\mathrm{Xu}, 2012$ ). In small-scale vegetable production, many farmers have attempted to overcome these challenges by adopting greenhouse production to control growing conditions and thereby improve the quality and quantity of output (Ti, Luo, and Yan, 2015). However, greenhouse production is relatively intensive in capital and labor, and endowment constraints can inhibit adoption by small-scale farm households or even limit the technical efficiency and output price because of food retailers' buyer power (Mugera and Langemeier, 2011; Sheldon, 2017; Wang et al., 2013).

In response to these challenges, the Chinese government in the early 2000s supported vertical coordination in the food supply chain and resource-provision contracts for small farmers. 
Studies for other countries have found a strong correlation between the contractual support provided to farmers and the degree of transformation of agricultural practices (Reardon et al., 2009). However, in the case of China, these government interventions largely failed. Huang et al. (2009), for example, found almost no written contracts in a survey of vegetable farmers in Shandong province.

Since the failure of vertical coordination and contracts to emerge, the Chinese government has provided policy and financial support for the creation of farmer professional cooperatives (FPCs) to act as an intermediary connecting farmers with upstream and downstream processes in the food supply chain (Huang and Liang, 2018; Yang, Klerkx, and Leeuwis, 2014). FPCs are conceptualized as nonneutral entities that assist farmers in attaining better positions in agricultural innovation systems and modern value chains (Hussein, 2001). FPCs typically provide services such as assistance in purchasing material inputs; guidance regarding new technologies, equipment, and production management practices; connections to modern marketing channels; and primary product processing (Deng et al., 2010; Yang, Klerkx, and Leeuwis, 2014). In 2017, there were about 1.9 million FPCs in China, with about $10 \%$ of these being vegetable cooperatives (Huang and Liang, 2018). For small farms in particular, FPCs can reduce the information and transaction costs associated with farm management and marketing (Hoken and $\mathrm{Su}$, 2018).

Existing studies find that cooperatives can play an important role in accelerating adoption of agricultural technologies, raising prices received by farmers via the market power that comes from aggregating numerous producers, and penetrating modern marketing channels (Abebaw and Haile, 2013; Cakir and Balagtas, 2012; Courtois and Subervie, 2015; Hoken and Su, 2018; Jia, Huang, and $\mathrm{Xu}, 2012$; Ma and Abdulai, 2016; Reardon et al., 2009). However, the benefits of participating in cooperatives are not uniform given differences among farmers in resource endowments, institutional arrangements, product types, market conditions, and managerial ability (Garnevska et al., 2011; Ito, Bao, and Su, 2012; Michelson, 2012; Reardon et al., 2009). In China, concerns have also been raised about the ownership and governance structure, capital constraints, small size, and management effectiveness of many FPCs (Huang and Liang, 2018; Xu et al., 2017). Jin et al. (2010) found that the rapid rates of productivity growth for horticultural crops in China were driven entirely by technological change, with declines over time in levels of technical efficiency (TE).

In empirically analyzing the impact of participating in a cooperative on TE and income, two issues should be carefully considered. First, because farms self-select into FPC participation, there may be selection bias because of either observable farm characteristics (e.g., size), unobserved characteristics (e.g., managerial ability), or both. Second, there may be differences in the production frontiers between FPC participants and nonparticipants because of the services provided by FPCs (O'Donnell, Rao, and Battese, 2008). We disentangle these issues by integrating the framework developed by Villano et al. (2015), which employs propensity score matching (PSM) and sample selection-corrected stochastic production frontier (SPF) analysis (Bravo-Ureta, Greene, and Solís, 2012), and a new approach to estimating the production metafrontier by Huang, Huang, and Liu (2014). The metafrontier is an overarching function that encompasses the deterministic components of stochastic frontier production functions for firms operating under different technologies (Battese, Rao, and O’Donnell, 2004).

The objective of this study is to estimate the impacts of FPCs in China on TE and income among greenhouse vegetable producers while addressing the two issues just mentioned. This study uses plot-level survey data for 2014 from 451 greenhouse vegetable farms in five regions of northern China that are the nation's primary producers of greenhouse vegetables. Greenhouse vegetable production has grown rapidly in China in recent years, and about one-third of total vegetable production in 2016 came from greenhouses. ${ }^{1}$

This study makes three contributions to the literature. First, it applies a methodologically rigorous procedure for estimating the impacts of FPC participation in a setting with cross-sectional

${ }^{1}$ Source: http://news.cctv.com/2017/09/18/ARTIYcw2vRCIknQh1V33oCc2170918.shtml (accessed July 10, 2019). 
data where the participation decision may depend on both observed and unobserved variables. Second, this study examines FPCs as one potential avenue for addressing a long-standing problem in China and other developing countries: how to increase incomes among small farm households. Third, unlike most impact evaluations in agriculture, which examine production or income, this study digs deeper by also examining TE. Agricultural growth can be decomposed into growth in inputs and productivity growth, and productivity growth can in turn be decomposed into technological change and improvements in TE. Each component of agricultural growth has a distinct set of driving factors (Bravo-Ureta et al., 2007), so that understanding how to foster agricultural growth requires an understanding of each component.

\section{Empirical framework}

\subsection{Propensity score matching}

If there are observed variables that are correlated with productivity and efficiency, as well as with participation in FPCs, then failure to account for self-selection in FPC participation will lead to biased estimates of the impacts of FPCs on TE and income. PSM can be used to construct a control group of nonparticipants who share similar observable characteristics to farmers participating in FPCs to address selection bias arising from observed variables (González-Flores et al., 2014; Todd, 2008).

We generate propensity scores using a binary choice model that incorporates the observed variables hypothesized to influence farmers' FPC participation decisions. The propensity scores are then used to identify a control group among the nonparticipants to match with the participant group (treatment group). There are a variety of algorithms in the literature for performing matches, including nearest-neighbor matching (NNM), caliper matching, radius matching, stratification matching, interval matching, kernel-based matching (KBM), and local linear matching (Caliendo and Kopeinig, 2008). Most of these algorithms limit the construction of matches to regions of common support, where the matches are sufficiently close. We tried NNM with caliper and KBM, which are two of the most popular algorithms, and selected NNM based on its better performance with our data.

With the treatment and control groups identified, the average treatment effect for the treated (ATT) can be estimated. The ATT is the average effect of treatment on those subjects (farms) who receive the treatment (FPC participation). The ATT is defined as

$$
\tau_{A T T}^{P S M}=E_{P(\boldsymbol{Z}) \mid I=1}\left\{E\left[R_{1} \mid I=1, P(\boldsymbol{Z})\right]-E\left[R_{0} \mid I=0, P(\boldsymbol{Z})\right]\right\} .
$$

$P(Z)$ represents the propensity scores, where $\boldsymbol{Z}$ is a vector of variables hypothesized to influence the participation decision. $R_{1}$ and $R_{0}$ are outcomes (e.g., income) for the treatment and control groups, respectively. $I=1$ indicates participation, and $I=0$ indicates nonparticipation.

\subsection{Sample selection-corrected group production frontiers}

Following Huang, Huang, and Liu (2014) and Villano et al. (2015), suppose that vegetable farmers are divided into two groups, FPC nonparticipants (group 0) and FPC participants (group 1), with all the farms in a given group sharing the same production frontier. The group sizes are $N_{0}$ and $N_{1}$, respectively. The group-specific SPFs can be written as

$$
\ln Y_{j i}=\ln f^{j}\left(\boldsymbol{X}_{j i}\right)+\varepsilon_{j i}=\ln f^{j}\left(\boldsymbol{X}_{j i}\right)+v_{j i}-u_{j i} .
$$

$Y_{j i}$ is the output of farm $i$ in the $j$ th group $\left(i=1, \ldots, N_{0}\right.$ for $j=0 ; i=N_{0}+1, \ldots, N_{0}+N_{1}$ for $j=1) . \boldsymbol{X}_{j i}$ denotes a vector of production inputs, $f^{j}(\cdot)$ is the group-specific production technology, $v_{j i}$ is a random error representing statistical noise and unobserved variables, $u_{j i} \geq 0$ is a nonnegative random error representing technical inefficiency that is independent of $v_{j i}$, and $\epsilon_{j i}=v_{j i}-u_{j i}$ is 
a composite error. $v_{j i}$ is assumed to be normally distributed with zero mean and group-specific variance $\sigma_{v j}^{2}$. $u_{j i}$ is assumed to follow a folded normal distribution (i.e., $u_{j i}=\left|U_{j i}\right|$ ), where $U_{j i}$ is a normally distributed random variable with zero mean and group-specific variance $\sigma_{u j}^{2}$. A farm's TE is defined as

$$
T E_{i}^{j}=\frac{Y_{j i}}{f^{j}\left(\boldsymbol{X}_{i}\right) e^{v_{j i}}}=e^{-u_{j i}} \leq 1 .
$$

Technical inefficiency arises when a farm produces less than the maximum possible output from the inputs it employs. TE can be increased through better managerial decisions. This study focuses on FPCs as a vehicle for improving farms' managerial ability.

To deal with biases from unobserved variables (e.g., managerial ability) within an SPF formulation, we employ the procedure introduced by Greene (2010), which is a sample selection correction for the stochastic frontier model. In this procedure, there is a probit sample selection equation:

$$
I_{i}=\operatorname{Probit}\left[\boldsymbol{\alpha}^{\prime} \boldsymbol{Z}_{i}+\omega_{i}\right] \text {. }
$$

$I_{j}=1$ if farm $i$ participates in an FPC, and $I_{i}=0$ if it does not participate. As previously, $Z_{i}$ is a vector of variables hypothesized to influence the participation decision, $\boldsymbol{\alpha}$ is a vector of parameters, and $\omega_{i}$ is a normally distributed error term with zero mean and unit variance. In the estimation of the SPF for nonparticipants, $v_{0 i}$ and $\omega_{i}$ are assumed to follow a bivariate normal distribution with correlation coefficient $\rho_{0}$. Similarly, in the estimation of the SPF for participants, $v_{1 i}$ and $\omega_{i}$ are assumed to follow a bivariate normal distribution with correlation coefficient $\rho_{1}$. The parameters $\rho_{0}$ and $\rho_{1}$ capture the presence or absence of selection bias from unobserved variables.

\subsection{Metafrontier production function}

After estimating the group-specific SPFs, we perform a likelihood ratio test to determine whether the TEs for the two groups can be explained by a common technology. If the null hypothesis of a common technology is rejected, and it is rejected with our data, the estimation can proceed following a metafrontier framework (Battese, Rao, and O’Donnell, 2004).

We use a procedure developed by Huang, Huang, and Liu (2014) to estimate the metafrontier. It involves quasi-maximum likelihood estimation of the following equation:

$$
\ln \hat{f}^{j}\left(\boldsymbol{X}_{j i}\right)=\ln f^{M}\left(\boldsymbol{X}_{j i}\right)+v_{j i}^{M}-u_{j i}^{M} .
$$

$\hat{f}^{j}\left(\boldsymbol{X}_{j i}\right)$. is the SPF estimate given previously of the frontier for farm $i$ in group $j, f^{M}\left(\boldsymbol{X}_{j i}\right)$ is the metafrontier production function to be estimated, $v_{j i}^{M}=\varepsilon_{j i}-\hat{\varepsilon}_{j i}$ is the error from the SPF estimation, and $u_{j i}^{M} \geq 0$ is a nonnegative error representing the gap between group $j$ 's production frontier and the metafrontier. $u_{j i}^{M}$ is assumed to be truncated normal— that is,

$$
u_{j i}^{M} \sim N^{+}\left[\mu^{M}\left(S_{j i}\right),\left(\sigma_{u}^{M}\right)^{2}\right] .
$$

$S_{j i}$ is a vector of variables representing the production environment for farm $i$ in group $j$. The vector $S_{j i}$ can include the services provided by FPCs to participants.

The gap between group j's production frontier and the metafrontier is known as the technology gap ratio (TGR), which is defined as

$$
T G R_{i}^{j}=\frac{f^{j}\left(X_{j i}\right)}{f^{M}\left(X_{j i}\right)}=e^{-u_{j i}^{M}} \leq 1 .
$$

The TGR can be attributed to a farmer's choice of a technique, which in our case is either participating or not participating in an FPC. Defined as the gap between group-specific production frontiers to the metafrontier, TGRs can also be seen as the result of technological change. Because FPCs are hypothesized to assist farmers in attaining a better production environment through 
access to agricultural innovation systems and modern value chains, this gap can also be referred to as an environment-technology gap ratio. A farm's metatechnical efficiency (MTE) is defined as its TE relative to the metafrontier, and is related to TE and the TGR as

$$
\operatorname{MTE}_{i}^{j}=\frac{Y_{j i}}{f^{M}\left(\boldsymbol{X}_{j i}\right) e^{v_{j i}^{M}}}=T G R_{i}^{j} \times T E_{i}^{j} \leq 1
$$

\section{Data, variables, and econometric model}

This article analyzes data collected in a household-level survey of greenhouse-grown vegetable planting in a large area of northern China that surrounds Beijing and consists of five provincesBeijing, Tianjin, Hebei, Liaoning, and Shandong. To facilitate our comparisons of greenhouse production between FPC participants and nonparticipants, we restricted the sampling frame to farmers who produced fruit vegetables (tomatoes, cucumbers, eggplants, and green peppers), which share similar production techniques and equipment. Based on the information from local agricultural offices, we carried out an initial investigation of the main greenhouse planting areas surrounding Beijing 1 year prior to the formal survey work. Then we randomly selected three greenhouse vegetable planting counties from each main greenhouse vegetable producing area, and then two random villages from each county, and obtained a total sample of 465 observations. Of those, 150 participated in an FPC and 315 did not. After removing observations with missing values on one or more variables in the analyses, the total sample became 451 (150 participants and 301 nonparticipants). As discussed subsequently, the PSM results indicated that 14 of the 301 nonparticipants were off support (i.e., not matched with the participants in terms of their propensity scores), reducing the samples for the groupspecific SPF and metafrontier estimations to 437 in total (150 participants and 287 nonparticipants).

Respondents completed a structured questionnaire composed of multiple modules covering their vegetable output, input allocation, technology adoption, marketing channel choices, and whether they were participating in an FPC. They were asked to report inputs and outputs for the entire previous year for their main greenhouse vegetable plot(s) (i.e., across all the growing seasons within the year), farm characteristics, and operator characteristics. Because the study focuses on greenhouse fruit vegetables, the rotation time(s) and greenhouse types, ${ }^{2}$ which are the main characteristics that vary depending on which crops are produced, were also included in the questionnaire to further improve the accuracy and reliability of our comparisons between FPC participants and nonparticipants.

Based on the literature and our experience, we hypothesized that both variables influencing farmers' income benefit and cost restrictions may affect farmers' decisions about joining FPCs, which also indicates their TE. Therefore, the vector of covariates $Z_{i}$ in the FPC participation equation (4) include farm size (hectares), family size, operator's age, operator's education (a dummy for whether or not the operator has attended senior high school), ${ }^{3}$ vegetable farming experience, rotation time(s), and greenhouse type. To capture how important vegetable production is to a farm, the share of farmland planted with vegetables is also included. Although the five provinces in the survey share similar climates and production techniques, three of them (Beijing, Tianjin, and Hebei) are a little different from the others because they are closer to the major population centers of Beijing and Tianjin. To capture this, we include a dummy variable for the Beijing-Tianjin-Hebei region. The results from estimation of equation (4) are used in PSM analyses.

\footnotetext{
${ }^{2}$ The farms surveyed here have two main types of greenhouses: (1) ordinary greenhouses that are not suitable for production in the winter and (2) warmhouses with heating to produce vegetables during the winter.

${ }^{3}$ Previous research (Dong, $\mathrm{Mu}$, and Ito, 2015) indicates that senior high school education provides farmers with skills and abilities that can aid in technology adoption to reduce technical inefficiencies, whereas less education does not.
} 
To facilitate comparability across vegetable farms in our sample operating at different scales, output and production inputs are measured on a per greenhouse basis for each farm. There are four production inputs $\left(\boldsymbol{X}_{j i}\right)$ in the group-specific production functions (2) and metafrontier production function (5): land (hectares per greenhouse), labor (days of work per greenhouse), fertilizer (chemical and organic fertilizers, plus manure, in yuan, per greenhouse), and an aggregate of other inputs (seeds, water, electricity, and primary processing fees, in yuan, per greenhouse). ${ }^{4}$

Output $\left(Y_{j i}\right)$ is measured by fruit vegetable income per greenhouse (in yuan). The commercialization ratios of the farmers surveyed are almost $100 \%$, so that income can be represented by the value of output. We measure output by value rather than quantity because value incorporates not only the quantity of each vegetable but also the mix of vegetables produced and price premiums or discounts based on quality, market timing, and other factors affected by farm management decisions. ${ }^{5}$ This means that observed technical inefficiencies in the group-specific production frontiers or the metafrontier may be because of producing too little quantity given the inputs at hand; producing a mix of vegetables that does not maximize income given the relative prices of different vegetables; selling at prices that are too low because of quality, timing, or other management decisions; or some combination of these three factors. This also means that our estimates of impacts of FPCs on TE may arise through one or more of these three management factors. ${ }^{6}$

We use a translog functional form for the group-specific production functions $f^{j}\left(\boldsymbol{X}_{j i}\right)$ and the metaproduction function $f^{M}\left(\boldsymbol{X}_{j i}\right)$ because it is more flexible in input-output relationships and input substitution possibilities than the standard Cobb-Douglas form. The translog can be written as

$$
\ln f^{k}\left(X_{i}\right)=\beta_{0}^{k}+\sum_{p}^{4} \beta_{p}^{k}\left(\ln X_{i p}\right)+1 / 2 \sum_{p=1}^{4} \sum_{q=1}^{4} \beta_{p q}^{k}\left(\ln X_{i p}\right)\left(\ln X_{i q}\right),
$$

where $k=0,1$ (group-specific production functions), or $M$ (metaproduction function). The $\beta$ 's are parameters to be estimated, with $\beta_{p q}^{k}=\beta_{q p}^{k}$ for all $p$ and $q$. The translog reduces to the Cobb-Douglas if $\beta_{p q}^{k}=0$ for all $p$ and $q$. A likelihood ratio test using the results given subsequently rejects the null hypothesis of a Cobb-Douglas form in favor of the translog.

With respect to the variables in the vector $S_{j i}$ affecting the metafrontier technology gap in equations (6) and (7), we include three FPC service variables, all of which are dummy variables: FPC assistance in materials purchasing, FPC provision of guidance on production technologies, and FPC-enabled access to marketing channels. We express the mean of the error term $\left(u_{j i}^{M}\right)$ representing the gap between group $j$ 's production frontier and the metafrontier as a linear function of these service variables:

$$
\mu^{M}\left(S_{j i}\right)=\delta^{\prime} S_{j i}
$$

where $\delta$ is a vector of parameters to be estimated, including an intercept.

\footnotetext{
${ }^{4} \mathrm{~A}$ potential source of measurement error for fertilizer and other inputs, because they are measured in value terms, is that their values may be affected by differences among farms in unit prices paid for these inputs that do not reflect differences in input quality.

${ }^{5}$ One potential drawback of measuring output by value is that prices may differ between FPC participants and nonparticipants or according to a variable such as farm location that may be associated with FPC participation. To test whether this is an issue in our case, we ran unit price tests both for FPC participants and nonparticipants and for farms inside and outside the Beijing-Tianjin-Hebei circle. In both cases, the means are close to each other, with $t$-statistics equal to -0.82 and -1.13 , which means that prices are not significantly different either by participation or by location. This may be attributable to significant improvements in recent years in transportation infrastructure, market infrastructure, and vegetable supply chains in the five provinces that are the focus of our study.

${ }^{6} \mathrm{With}$ respect to inputs, figures in Table 1 indicate significant heterogeneity among farms in input usage, especially fertilizer and the "other inputs" aggregate. The figures in Table 1 also show that FPC participants are significantly less likely than nonparticipants to have a warmhouse, and that participants plant fewer rotations of vegetables per year than nonparticipants. These two factors would tend to work against the TE of FPC participants relative to nonparticipants, and yet our results indicate that participants have significantly higher levels of TE than nonparticipants.
} 
Table 1. Summary statistics

\begin{tabular}{|c|c|c|c|c|}
\hline \multirow[b]{2}{*}{ Variable } & \multicolumn{2}{|c|}{ FPC Participants } & \multicolumn{2}{|c|}{ FPC Nonparticipants } \\
\hline & Mean & Standard Deviation & Mean & Standard Deviation \\
\hline \multicolumn{5}{|c|}{ Sample selection equation and propensity score matching } \\
\hline Farm size (hectares) & 0.657 & 0.277 & 0.533 & 0.117 \\
\hline Family size (people) & 3.940 & 0.113 & 4.051 & 0.084 \\
\hline Operator age (years) & $49.04^{\star}$ & 0.706 & 47.410 & 0.482 \\
\hline $\begin{array}{l}\text { Operator has senior high school } \\
\text { education (yes }=1, \text { no }=0 \text { ) }\end{array}$ & $0.480^{\star * *}$ & 0.041 & 0.352 & 0.027 \\
\hline $\begin{array}{l}\text { Vegetable farming experience } \\
\text { (years) }\end{array}$ & 15.033 & 8.273 & 15.430 & 8.377 \\
\hline Rotations per year (number) & $1.360^{\star \star}$ & 0.055 & 1.495 & 0.037 \\
\hline $\begin{array}{l}\text { Greenhouse type (ordinary }=1 \text {, } \\
\text { warmhouse }=0 \text { ) }\end{array}$ & $0.747^{\star \star \star}$ & 0.036 & 0.571 & 0.028 \\
\hline Vegetable planting share (\%) & $72.250^{\star *}$ & 5.202 & 72.452 & 1.702 \\
\hline $\begin{array}{l}\text { Beijing-Tianjin-Hebei region } \\
(\text { yes }=1, \text { no }=0)\end{array}$ & $0.647^{\star \star \star}$ & 0.039 & 0.521 & 0.028 \\
\hline \multicolumn{5}{|l|}{ Output and inputs } \\
\hline $\begin{array}{l}\text { Vegetable income } \\
\text { (yuan per greenhouse) }\end{array}$ & $28,851^{\star *}$ & 1,451 & 25,236 & 1,027 \\
\hline Land (hectares per greenhouse) & $0.668^{\star \star \star}$ & 0.023 & 0.823 & 0.027 \\
\hline Labor (days per greenhouse) & 205 & 6.864 & 193 & 4.812 \\
\hline Fertilizer (yuan per greenhouse) & 3,854 & 6,525 & 3,221 & 4,969 \\
\hline Other inputs (yuan per greenhouse) & 3,575 & 4,202 & 3,516 & 5,080 \\
\hline \multicolumn{5}{|l|}{ Metafrontier technology gap } \\
\hline $\begin{array}{l}\text { FPC assistance in materials } \\
\text { purchasing (yes }=1, \text { no }=0 \text { ) }\end{array}$ & $0.727^{\star \star \star}$ & 0.036 & 0 & - \\
\hline $\begin{array}{l}\text { FPC guidance on technologies } \\
(\text { yes }=1, \text { no }=0)\end{array}$ & $0.713^{\star \star \star}$ & 0.037 & 0 & - \\
\hline $\begin{array}{l}\text { FPC-enabled access to marketing } \\
\text { channels (yes }=1, \text { no }=0 \text { ) }\end{array}$ & $0.480^{\star \star \star}$ & 0.409 & 0 & - \\
\hline
\end{tabular}

Note: Asterisks $\left({ }^{\star \star \star},{ }^{\star \star}\right.$, and $\left.{ }^{\star}\right)$ denote differences in the means between farmer professional cooperative (FPC) participants and nonparticipants that are significant at the $1 \%, 5 \%$, and $10 \%$ levels, respectively.

Table 1 presents summary statistics for the variables in the econometric model, for FPC participants and nonparticipants. In terms of the variables entering the sample selection equation and PSM, compared with nonparticipants, participants on average are older, have a higher average level of education, do fewer rotations of vegetable crops per year, are more likely to have ordinary greenhouses (as opposed to warmhouses), devote a slightly smaller percentage of their land area to vegetables, and are more likely to be located in the Beijing-Tianjin-Hebei region. Looking at output and inputs, participants on average have a higher vegetable income than nonparticipants. The FPC service variables are equal to 0 for all nonparticipants. Among participants, more than twothirds received FPC assistance in materials purchasing (73\%) and guidance on technologies (71\%). About one-half (48\%) received assistance in accessing marketing channels. 
Table 2. Probit estimates of farmer professional cooperative participation

\begin{tabular}{|c|c|c|}
\hline Variable & Estimated Coefficient & Standard Error \\
\hline Farm size & 0.0005 & 0.001 \\
\hline Family size & 0.0742 & 0.104 \\
\hline Operator age & $0.023^{\star \star *}$ & 0.009 \\
\hline Operator has senior high school education & $0.453^{\star \star \star}$ & 0.136 \\
\hline Vegetable farming experience & -0.008 & 0.008 \\
\hline Rotations per year & $-0.264^{\star \star}$ & 0.105 \\
\hline Greenhouse type & $0.446^{\star \star \star}$ & 0.139 \\
\hline Vegetable planting share & -0.002 & 0.003 \\
\hline Beijing-Tianjin-Hebei region & $0.394^{\star \star \star}$ & 0.142 \\
\hline Constant & $-1.785^{\star \star \star}$ & 0.602 \\
\hline Number of observations & \multicolumn{2}{|l|}{451} \\
\hline Log-likelihood function & \multicolumn{2}{|c|}{-267.565} \\
\hline Likelihood ratio $\chi^{2}$ & \multicolumn{2}{|l|}{33.64} \\
\hline
\end{tabular}

Note: Asterisks $\left({ }^{\star \star \star},{ }^{\star \star}\right.$, and $\left.{ }^{\star}\right)$ denote significance at $1 \%, 5 \%$, and $10 \%$ levels, respectively.

\section{Estimation results}

\subsection{Propensity score matching}

Probit estimates of the sample selection equation (4) are in Table 2. These results are used to generate propensity scores. Farm operators with a senior high school education are more likely to participate in FPCs, which is consistent with the literature (e.g., Wollni and Zeller, 2007) and is often attributed to the greater ability of more educated farmers to access, process, and act on new information. Farms with ordinary greenhouses or fewer crop rotations per year are more likely to participate in FPCs. These farms face more risk because they are more limited in their ability to change production plans based on the weather or market situation. For them, participating in an FPC may be a risk-reduction strategy. Farms located in the Beijing-Tianjin-Hebei region are more likely to participate, which makes sense because the greater economic development and clustering of agribusinesses in this region mean that FPCs have more to offer participants.

Results of balancing tests for PSM are shown in the Appendix (Table A1). We tried two popular matching algorithms, NNM with caliper and KBM, and NNM was selected based on its superior performance with better-matched and balanced samples. Figure 1 presents the distribution of support for the treated (participants) and untreated (nonparticipants) using the NNM results. The samples are balanced with only 14 nonparticipants (4\%) off support (i.e., not matched with the participants in terms of their propensity scores), and none of the participants off support (not matched with the nonparticipants). This implies that selection bias from observables is not a major issue with our data. After removing the 14 nonparticipants who are off support, the samples for the SPF and metafrontier estimations became 150 participants and 287 nonparticipants (437 total).

\subsection{Sample selection-corrected group production frontiers}

The sample selection-corrected, group-specific SPF estimation results using matched samples are shown in Table 3. The results in Table 3 indicate that there are important differences between the 
Table 3. Sample selection-corrected stochastic production frontier model estimates using matched samples

\begin{tabular}{|c|c|c|c|c|}
\hline \multirow[b]{2}{*}{ Variables } & \multicolumn{2}{|c|}{ Participants $(j=1)$} & \multicolumn{2}{|c|}{ Nonparticipants $(j=0)$} \\
\hline & Estimated Coefficient & Standard Error & Estimated Coefficient & Standard Error \\
\hline Constant & $0.423^{\star \star}$ & 0.192 & $0.235^{\star \star}$ & 0.110 \\
\hline In land & $0.600^{\star \star \star}$ & 0.120 & 0.119 & 0.089 \\
\hline In labor & $0.508^{\star \star \star}$ & 0.106 & 0.038 & 0.092 \\
\hline In fertilizer & $0.201^{\star \star \star}$ & 0.053 & $0.252^{\star \star \star}$ & 0.052 \\
\hline In other inputs & -0.067 & 0.084 & $0.234^{\star \star \star}$ & 0.056 \\
\hline $0.5 \times(\ln \text { land })^{2}$ & $0.522^{*}$ & 0.316 & -0.057 & 0.097 \\
\hline $0.5 \times(\ln \text { labor })^{2}$ & 0.102 & 0.260 & 0.109 & 0.112 \\
\hline $0.5 \times(\text { In fertilizer })^{2}$ & $0.022^{*}$ & 0.012 & $0.035^{\star \star \star}$ & 0.012 \\
\hline $0.5 \times(\text { ln other inputs })^{2}$ & 0.034 & 0.079 & 0.016 & 0.050 \\
\hline In land $\times$ In labor & 0.246 & 0.410 & $0.262^{*}$ & 0.141 \\
\hline In land $x$ In fertilizer & $0.216^{\star}$ & 0.131 & -0.063 & 0.099 \\
\hline In land $x$ ln other inputs & -0.370 & 0.253 & 0.067 & 0.132 \\
\hline In labor $\times$ In fertilizer & 0.077 & 0.152 & 0.094 & 0.104 \\
\hline In labor $\times$ In other inputs & -0.253 & 0.203 & -0.106 & 0.124 \\
\hline In fertilizer $\times$ In other inputs & -0.044 & 0.059 & -0.123 & 0.046 \\
\hline$\sigma_{u j}$ & $0.426^{\star \star \star}$ & 0.138 & $0.549^{\star \star \star}$ & 0.127 \\
\hline$\sigma_{v j}$ & $0.269^{\star \star \star}$ & 0.068 & $0.450^{\star \star \star}$ & 0.046 \\
\hline$\rho_{j}$ & 0.105 & 0.503 & $-0.564^{\star}$ & 0.330 \\
\hline Sample size & \multicolumn{2}{|l|}{150} & \multicolumn{2}{|l|}{287} \\
\hline Log-likelihood function & \multicolumn{2}{|l|}{-216.67} & \multicolumn{2}{|c|}{-348.35} \\
\hline
\end{tabular}

Notes: The variables used in the estimation are normalized by their geometric means, so that the first-order estimates are partial output elasticities with respect to individual inputs at geometric mean values. Asterisks ( ${ }^{\star \star \star},{ }^{\star \star}$, and ${ }^{\star}$ ) denote significance at $1 \%, 5 \%$, and $10 \%$ levels, respectively.

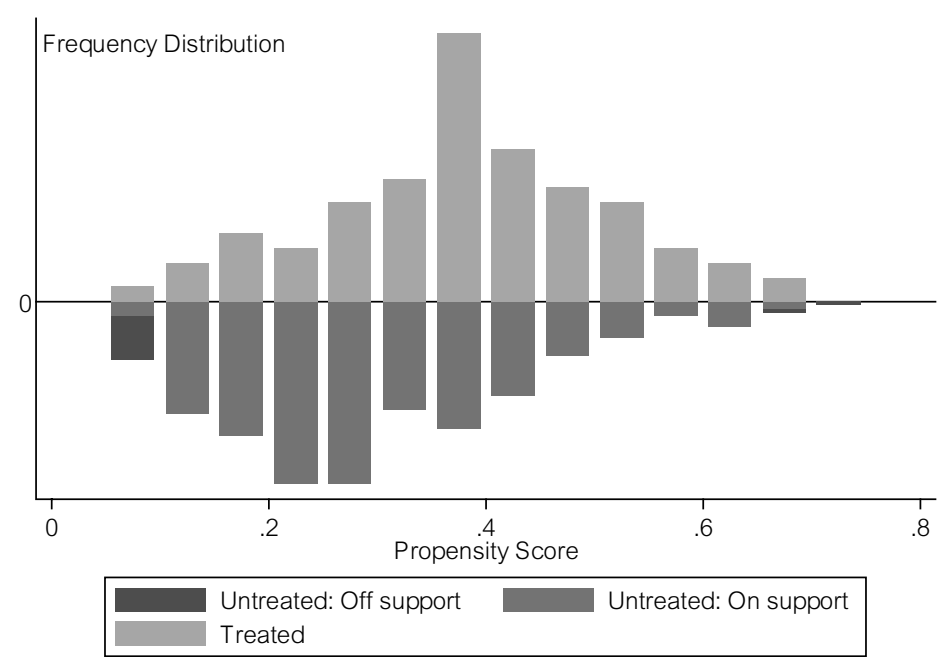

Figure 1. Distribution and common support for propensity score matching. 
SPFs for participants and nonparticipants, suggesting that FPCs change the production technologies used by their member farms. We ran a likelihood ratio test of a null hypothesis of equality in production function parameter values between participants and nonparticipants, and the null hypothesis was rejected $\left(X^{2}=86.52, P<0.001\right)$.

The variables used in the estimation of the Table 3 results were normalized by their geometric means, so that the first-order estimated coefficients on the inputs (estimates of the $\beta_{p}^{k}$ in equation 9) are partial output elasticities with respect to individual inputs when evaluated at their geometric mean values. For example, the estimated partial output elasticity of land at the sample geometric means for participants is about 0.6. The sum of the partial output elasticities for participants is greater than 1 (about 1.2), indicating increasing returns to scale per greenhouse. For nonparticipants, the sum of the partial output elasticities is significantly less than 1 (about 0.6 ), indicating decreasing returns to scale per greenhouse.

For both participants and nonparticipants, the estimated coefficient on the log squared of fertilizer is positive and statistically significant, which indicates that the partial output elasticity of fertilizer increases as fertilizer use increases. For participants, the estimated coefficient on the log squared of land is positive and statistically significant, indicating that the partial output elasticity of land increases as farm size increases. The significant positive coefficient on the land-fertilizer interaction term for participants suggests a complementary relationship between these two inputs, in the sense that an increase in one of these two inputs will raise the partial output elasticity of the other. The significant positive coefficient on the land-labor term for nonparticipants points to a similar complementary relationship for those two inputs. The sample mean estimate of the partial output elasticity of labor is about 0.60 and statistically significant for participants, but only about 0.12 and not statistically significant for nonparticipants. For land, the estimated partial output elasticity is about 0.51 for participants and statistically significant, versus 0.04 and not statistically significant for nonparticipants. This suggests that FPCs help participants get a greater percentage boost in output than nonparticipants from additional land or labor.

The estimated partial output elasticity for other inputs (seeds, water, electricity, and primary processing fees) is about 0.23 and statistically significant for nonparticipants, whereas it is close to zero and not statistically significant for participants. This suggests that FPC participants may be maximizing output with respect to these other inputs, which in turn suggests an allocative inefficiency because these inputs have a cost. At sample geometric means, the estimated marginal product of other inputs for nonparticipants is about 1.7 but is not statistically different at the $5 \%$ significance level from its allocatively efficient value of 1 . Similarly, the estimated marginal product of fertilizer for participants (1.5) is not statistically different from 1 at the $5 \%$ level. However, for nonparticipants, the estimated marginal product for fertilizer (2.0) is significantly different from 1 at the 5\% level. Other studies (e.g., Chen, Huffman, and Rozelle, 2009) have also found significant departures from allocative efficiency in Chinese agriculture.

The estimate of the selectivity from unobservables parameter for participants $\left(\rho_{1}\right)$ is not statistically significant. However, the estimate of this parameter for nonparticipants $\left(\rho_{0}\right)$ is statistically significant at the $10 \%$ level, which suggests that estimating the SPF model within a sample selection framework is justified. The estimate of $\rho_{0}$ is negative, implying that the selection bias is negative, with unobserved factors positively predisposing farms toward FPC participation that also tend to reduce their output. Managerial ability is often cited as an example of an unobserved variable in these contexts (e.g., Bravo-Ureta, Greene, and Solís, 2012; Huang, Huang, and Liu, 2014; Villano et al., 2015). In this case, if it is managerial ability, farms with weaker management skills, and therefore less output, may be looking at FPC participation to compensate for this. Ma and Abdulai (2016) also found negative selection bias in their study of FPCs for apple farms in China.

In addition to sample selection SPF models, it is also possible to follow Bravo-Ureta, Greene, and Solís (2012) and Villano et al. (2015) in estimating so-called conventional SPF models on the matched data, with an inverse Mills ratio variable $(\lambda)$ included to account for sample selection (i.e., a Heckman-type correction). As Greene (2010) indicates, the conventional approach is inferior to 
Table 4. Estimates of the stochastic metafrontier

\begin{tabular}{|c|c|c|}
\hline Variables & Estimated Coefficient & Robust Standard Error \\
\hline \multicolumn{3}{|l|}{ Technical structure model, equation (5) } \\
\hline Constant & $0.072^{\star \star \star}$ & 0.024 \\
\hline In land & $0.210^{\star * *}$ & 0.041 \\
\hline In labor & $0.155^{\star \star \star}$ & 0.039 \\
\hline In fertilizer & $0.216^{\star \star \star}$ & 0.020 \\
\hline In other inputs & $0.174^{\star \star \star}$ & 0.025 \\
\hline $0.5 \times(\ln \text { land })^{2}$ & -0.039 & 0.054 \\
\hline $0.5 \times(\ln \text { labor })^{2}$ & $0.104^{\star \star}$ & 0.048 \\
\hline $0.5 \times(\ln \text { fertilizer })^{2}$ & $0.027^{\star \star \star}$ & 0.004 \\
\hline $0.5 \times(\text { In other inputs })^{2}$ & -0.011 & 0.021 \\
\hline In land $\times$ In labor & $0.231^{\star \star \star}$ & 0.076 \\
\hline In land $\times$ In fertilizer & 0.042 & 0.040 \\
\hline In land $x$ In other inputs & 0.079 & 0.060 \\
\hline In labor $\times$ In fertilizer & $0.088^{\star \star}$ & 0.040 \\
\hline In labor $\times$ In other inputs & $-0.130^{\star \star \star}$ & 0.052 \\
\hline In fertilizer $\times$ In other inputs & $-0.084^{\star \star \star}$ & 0.017 \\
\hline \multicolumn{3}{|l|}{ Technical inefficiency model, equation (10) } \\
\hline Constant & $0.101^{\star \star}$ & 0.049 \\
\hline FPC assistance in materials purchasing & $-0.417^{\star \star}$ & 0.209 \\
\hline FPC guidance on technologies & -0.204 & 0.257 \\
\hline FPC-enabled access to marketing channels & $-0.372^{*}$ & 0.218 \\
\hline$\left(\sigma_{\varepsilon}^{M}\right)^{2}=\left(\sigma_{v}^{M}\right)^{2}+\left(\sigma_{u}^{M}\right)^{2}$ & $0.111^{\star \star \star}$ & 0.008 \\
\hline$\gamma^{M}=\left(\sigma_{v}^{M}\right)^{2} /\left[\left(\sigma_{v}^{M}\right)^{2}+\left(\sigma_{u}^{M}\right)^{2}\right]$ & $0.106^{\star \star \star}$ & 0.044 \\
\hline Log-likelihood function & \multicolumn{2}{|c|}{-128.054} \\
\hline
\end{tabular}

Notes: The variables used in the estimation of the technical structure model are normalized by their geometric means, so that the first-order estimates are partial output elasticities with respect to individual inputs at geometric mean values. Asterisks (***,

**, and ${ }^{*}$ ) denote significance at $1 \%, 5 \%$, and $10 \%$ levels, respectively. FPC, farmer professional cooperative.

the sample selection SPF approach, but it still yields a feasible consistent estimator of the production function parameters. We estimated three models using the conventional approach: one pooled model of both participants and nonparticipants, one for only participants, and one for only nonparticipants. ${ }^{7}$ The estimates of $\lambda$ were all statistically significant, which again suggests that there is unobserved selection bias that should be controlled.

\subsection{Metafrontier production function}

Table 4 presents estimates of the parameters of the stochastic metafrontier (SMF). Again, the firstorder estimated coefficients (the $\beta_{p}^{k}$ in equation 9) are partial output elasticities with respect to individual inputs when evaluated at their geometric mean values. The sum of the partial output

\footnotetext{
${ }^{7}$ These results are available from the authors upon request.
} 
elasticities is less than 1 (about 0.8), indicating decreasing returns to scale along the metafrontier. Similar to the group-specific SPF results, the estimated marginal products for fertilizer (1.7) and other inputs (1.4) are both greater than 1, and in this case, both are statistically different from 1 at a $5 \%$ significance level. Also similar to the group-specific SPF results, the partial output elasticity of fertilizer increases as fertilizer use increases, and land has complementary relationships with labor and fertilizer.

Results show that two of the FPC services can help its member farmers reduce the technical inefficiency component of the model. The estimated coefficient for FPC materials purchasing and FPC-enabled access to marketing channels is negative and statistically significant, indicating that these services can help make the member farmers' group production frontier closer to the metafrontier to get better TGRs. The estimated coefficient for FPC guidance on technologies is also negative but not statistically significant. This result may come from the fact that although new technologies were applied to increase output and/or reduce costs, the producers are not able to fully master each new technique before an even newer, better one becomes available and is adopted, so the overall effect of the technology guidance from FPCs is not obvious.

\subsection{Impacts of farmer professional cooperative participation}

Estimated gaps in TE and income for FPC participants and nonparticipants are presented in Table 5. These estimated gaps are based on the sample selection SPF model results in Table 3 and the SMF results in Table 4, which in turn are based on the matched samples of FPC participants and nonparticipants. The income gap is defined as the difference in output value between the fitted group-specific frontier and the metafrontier. The income gap is always negative, and a smaller absolute value for the income gap means a better output performance.

The figures in Table 5 indicate that FPC participants outperform nonparticipants on average in TE, MTE, and the income gap. In comparison of group-specific TE, most FPC participants are closer to their SPF with an average group-specific TE of 0.72, whereas that of nonparticipants is 0.66. This result indicates that FPCs can help their participants to reduce the inner TE gap through relative uniform production arrangements. The average TGR for participants (0.96) is statistically significantly higher than that of nonparticipants $(0.89)$, which means the group-specific production frontier for participants is closer to the metafrontier than the production frontier for nonparticipants with the help of the FPC services. This result also indicates that the performance of technological change for participants is better than nonparticipants. Therefore, FPC participants have a better overall average MTE (0.69) than nonparticipants (0.59). In terms of income, the gap for participants and nonparticipants $[-¥ 3,134-(-¥ 7,594)=¥ 4,460]$ is sizeable and is equal to about one-sixth $(18 \%)$ of mean income per greenhouse for nonparticipants.

\section{Discussion and Conclusions}

FPCs, which help connect small-scale farmers in China with input markets, new agricultural technologies, and modern marketing channels, have gained considerable support from the Chinese government in recent years. This study combines PSM techniques with a selection-corrected stochastic metafrontier analysis to estimate the effects of participation in FPCs on TE and income. Combining these models permits us to control for potential selection bias on the part of the farmers in deciding whether to participate in an FPC stemming from both observed and unobserved variables.

Our results suggest that nonparticipants may have incentives to join FPCs to increase their income. The estimated income gap for participants and nonparticipants $[-¥ 3,134-(-¥ 7,594)=$ $¥ 4,460$ ] is significant and equal to about one-sixth (18\%) of mean income per greenhouse for nonparticipants. In conducting our survey, we found that FPCs were established in just $51 \%$ of the villages in the five provinces studied, and that only $32 \%$ of the vegetable farmers in those villages were FPC 
Table 5. Technical and income gaps between participants and nonparticipants

\begin{tabular}{|c|c|c|c|c|}
\hline Item & Mean & Standard Deviation & Minimum & Maximum \\
\hline \multicolumn{5}{|l|}{ Participants } \\
\hline $\mathrm{TE}$ & $0.72^{\star \star \star}$ & 0.12 & 0.36 & 0.91 \\
\hline TGR & $0.96^{\star \star \star}$ & 0.03 & 0.68 & 0.98 \\
\hline MTE & $0.69^{\star \star \star}$ & 0.12 & 0.34 & 0.86 \\
\hline Income gap & $-3,134^{\star \star \star}$ & -961 & $-1,626$ & $-7,240$ \\
\hline \multicolumn{5}{|c|}{ Nonparticipants } \\
\hline $\mathrm{TE}$ & 0.66 & 0.12 & 0.23 & 0.90 \\
\hline TGR & 0.89 & 0.02 & 0.84 & 0.96 \\
\hline MTE & 0.59 & 0.12 & 0.22 & 0.81 \\
\hline Income gap & $-7,594$ & $-13,881$ & -349 & $-176,521$ \\
\hline
\end{tabular}

Notes: The income gap is defined as the difference in output value between the fitted group-specific frontier and the metafrontier and is always negative. A smaller absolute value for the income gap means a better output performance. Asterisks $\left({ }^{\star \star \star},{ }^{\star \star}\right.$, and $\left.{ }^{\star}\right)$ denote mean differences between participants and nonparticipants, which are significant at $1 \%$, $5 \%$, and $10 \%$ levels, respectively. MTE, metatechnical efficiency; TE, technical efficiency; TGR, technology gap ratio.

participants. The Chinese government should encourage development of additional FPCs and enlargement of cross-village FPCs for villages that are too small to support an FPC on their own.

Many questions remain regarding the most effective services an FPC can offer to improve the productivity and TE of farmers. Most FPCs also provide some assistance to "informal" member farmers who have not officially joined the cooperative. We are aware of one other study (Deng et al., 2010) that has addressed differences between formal members and informal members who are typically more loosely associated with the FPC, although they are included in many activities. It would also be helpful to examine how the impacts of FPCs may vary depending on the attributes of the locations where they are established, such as infrastructure, proximity to markets, and market size. That was not feasible with our study because all five provinces in our survey sample have seen significant improvements in recent years in transportation infrastructure, market infrastructure, and vegetable supply chains.

As a caveat, our use of cross-sectional data restricts our analysis while providing opportunities for future study. Future access to panel data for inputs and outputs would allow for a more comprehensive analysis that could capture spillover effects of a farm's participation in an FPC on neighboring farms in subsequent years. Panel data would also make it possible to identify whether the impacts of FPC participation grow over time because of learning by doing by participating farmers and FPC personnel.

Author ORCIDs. (D) Ying Dong 0000-0003-2443-317X

Financial support. This work was supported by Fruit Vegetables Industry Technology System of Beijing Innovation Team (Grant No. BAIC01-2016), the Major Project Fund of Social Science of Beijing (Grant No. 15JGA020), the National Natural Science Foundation of China (Grant Nos. 71773121 and 71803052), and the National Social Science Foundation of China (Grant No. 18ZDA074).

\section{References}

Abebaw, D., and M.G. Haile. "The Impact of Cooperatives on Agricultural Technology Adoption: Empirical Evidence from Ethiopia.” Food Policy 38(February 2013):82-91.

Battese, G.E., D.S.P. Rao, and C.J. O'Donnell. “A Metafrontier Production Function for Estimation of Technical Efficiencies and Technology Gaps for Firms Operating under Different Technologies.” Journal of Productivity Analysis 21, 1(2004): 91-103. 
Bravo-Ureta, B.E., W. Greene, and D. Solís. "Technical Efficiency Analysis Correcting for Biases from Observed and Unobserved Variables: An Application to a Natural Resource Management Project." Empirical Economics 43, 1(2012):55-72.

Bravo-Ureta, B.E., D. Solís, V.H. Moreira López, J.F. Maripani, A. Thiam, and T. Rivas. "Technical Efficiency in Farming: A Meta-regression Analysis." Journal of Productivity Analysis 27, 1(2007):57-72.

Cakir, M., and J.V. Balagtas. "Estimating Market Power of U.S. Dairy Cooperatives in the Fluid Milk Market." American Journal of Agricultural Economics 94, 3(2012):647-58.

Caliendo, M., and S. Kopeinig. "Some Practical Guidance for the Implementation of Propensity Score Matching." Journal of Economic Surveys 22, 1(2008):31-72.

Chen, Z., W.E. Huffman, and S. Rozelle. "Farm Technology and Technical Efficiency: Evidence from Four Regions in China." China Economic Review 20, 2(2009):153-61.

Courtois, P., and J. Subervie. "Farmer Bargaining Power and Market Information Services." American Journal of Agricultural Economics 97, 3(2015):953-77.

Deng, H., J. Huang, Z. Xu, and S. Rozelle. "Policy Support and Emerging Farmer Professional Cooperatives in Rural China." China Economic Review 21, 4(2010):495-507.

Dong, Y., Y. Mu, and S. Ito. "Endogenous Agricultural Technology Diffusion with Factor Structural Changes in China." Journal of the Faculty of Agriculture Kyushu University 60, 2(2015):519-28.

Garnevska, E., G. Liu, and N.M. Shadbolt. "Factors for Successful Development of Farmer Cooperatives in Northwest China." International Food and Agribusiness Management Review 14, 4(2011):69-84.

González-Flores, M., B.E. Bravo-Ureta, D. Solís, P. Winters. "The Impact of High Value Markets on Smallholder Productivity in the Ecuadorean Sierra: A Stochastic Production Frontier Approach Correcting for Selectivity Bias.” Food Policy 44(February 2014):237-47.

Greene, W. "A Stochastic Frontier Model with Correction for Sample Selection." Journal of Productivity Analysis 34, 1(2010):15-24.

Hoken, H., and Q. Su. "Measuring the Effect of Agricultural Cooperatives on Household Income: Case Study of a RiceProducing Cooperative in China." Agribusiness: An International Journal 34, 4(2018):831-46.

Hu, R., Y. Cai, K.Z. Chen, and J. Huang. "Effects of Inclusive Public Agricultural Extension Service: Results from a Policy Reform Experiment in Western China." China Economic Review 23, 4(2012):962-74.

Huang, C.J., T.H. Huang, and N.H. Liu. "A new Approach to Estimating the Metafrontier Production Function Based on a Stochastic Frontier Framework.” Journal of Productivity Analysis 42, 3(2014):241-54.

Huang, J., H. Zhi, Z. Huang, X. Jia and S. Rozelle. "Smallholder Incomes, Vegetable Marketing and Food Safety: Evidence from China." Paper presented at the International Association of Agricultural Economists Conference, Beijing, China, August 16-22, 2009. Internet site: https://ageconsearch.umn.edu/bitstream/51653/2/424.pdf (Accessed March 22, 2018).

Huang, Z., and Q. Liang. "Agricultural Organizations and the Role of Farmer Cooperatives in China since 1978: Past and Future.” China Agricultural Economic Review 10, 1(2018):48-64.

Hussein, K. "Producer Organizations and Agricultural Technology in West Africa: Institutions That Give Farmers a Voice." Development 44, 4(2001):61-66.

Ito, J., Z. Bao, and Q. Su. "Distributional Effects of Agricultural Cooperatives in China: Exclusion of Smallholders and Potential Gains on Participation.” Food Policy 37, 6(2012):700-709.

Jia, X., J. Huang, and Z. Xu. "Marketing of Farmer Professional Cooperatives in the Wave of Transformed Agrofood Market in China." China Economic Review 23, 3(2012):665-74.

Jin, S., H. Ma, J. Huang, R. Hu, and S. Rozelle. "Productivity, Efficiency and Technical Change: Measuring the Performance of China's Transforming Agriculture.” Journal of Productivity Analysis 33, 3(2010):191-207.

Ma, W., and A. Abdulai. "Does Cooperative Membership Improve Household Welfare? Evidence from Apple Farmers in China." Food Policy 58(January 2016):94-102.

Michelson, H.C. "Small Farmers, NGOs, and a Walmart World: Welfare Effects of Supermarkets Operating in Nicaragua." American Journal of Agricultural Economics 95, 3(2012):628-49.

Mugera, A.W., and M.R. Langemeier. "Does Farm Size and Specialization Matter for Productive Efficiency? Results from Kansas." Journal of Agricultural and Applied Economics 43, 4(2011):515-28.

O'Donnell, C.J., D.S.P. Rao, and G.E. Battese. "Metafrontier Frameworks for the Study of Firm-Level Efficiencies and Technology Ratios.” Empirical Economics 34, 2(2008):231-55.

Reardon, T., C.B. Barrett, J.A. Berdegué, and J.F.M. Swinnen. “Agrifood Industry Transformation and Small Farmers in Developing Countries.” World Development 37, 11(2009):1717-27.

Sheldon, I.M. "The Competitiveness of Agricultural Product and Input Markets: A Review and Synthesis of Recent Research." Journal of Agricultural and Applied Economics 49, 1(2017):1-44.

Ti, C., Y. Luo, and X. Yan. "Characteristics of Nitrogen Balance in Open-Air and Greenhouse Vegetable Cropping Systems of China." Environmental Science and Pollution Research 22, 23(2015):18508-18.

Todd, P.E. "Evaluating Social Programs with Endogenous Program Placement and Selection of the Treated." Handbook of Development Economics. T.P. Schultz and J. Strauss, eds. Amsterdam: Elsevier, 2008, pp. 3847-94. 
Villano, R., B. Bravo-Ureta, D. Solis, and E. Fleming. "Modern Rice Technologies and Productivity in the Philippines: Disentangling Technology from Managerial Gaps.” Journal of Agricultural Economics 66, 1(2015):129-54.

Wang, H., X. Dong, S. Rozelle, J. Huang, and T. Reardon. "Producing and Procuring Horticultural Crops with Chinese Characteristics: The Case of Northern China." World Development 37, 11(2009):1791-801.

Wang, H., F. Yu, T. Reardon, J. Huang, and S. Rozelle. "Social Learning and Parameter Uncertainty in Irreversible Investments: Evidence from Greenhouse Adoption in Northern China." China Economic Review 27(December 2013):104-20.

Wollni, M., and M. Zeller. "Do Farmers Benefit from Participating in Specialty Markets and Cooperatives? The Case of Coffee Marketing in Costa Rica." Agricultural Economics 37, 2-3(2007):243-48.

Xu, Y., G.W.J. Hendrikse, H. Guo, and Q. Liang. “Characterizing Cooperatives in China.” Management and Governance of Networks: Franchising, Cooperatives, and Strategic Alliances. G. Hendrikse, G. Cliquet, T. Ehrmann, and J. Windsperger, eds. Cham, Switzerland: Springer, 2017, pp. 213-31.

Yang, H., L. Klerkx, and C. Leeuwis. "Functions and Limitations of Farmer Cooperatives as Innovation Intermediaries: Findings from China.” Agricultural Systems 127(May 2014):115-25.

\section{Appendix}

Table A1. Balancing test for propensity score matching

\begin{tabular}{|c|c|c|c|c|c|c|}
\hline \multirow[b]{2}{*}{ Variable } & \multicolumn{3}{|c|}{ NNM with Caliper } & \multicolumn{3}{|c|}{ KBM } \\
\hline & $\%$ Mean Bias & $t$-Ratio & $\mathrm{V}(\mathrm{T}) / \mathrm{V}(\mathrm{C})$ & $\%$ Mean Bias & t-Ratio & $\mathrm{V}(\mathrm{T}) / \mathrm{V}(\mathrm{C})$ \\
\hline Operator age & 4.0 & 0.04 & 0.95 & -0.6 & -0.05 & 1.04 \\
\hline Operator has senior high school education & -4.5 & -0.26 & 1 & -3.5 & -0.29 & 1 \\
\hline Vegetable farming experience & 4.0 & 0.49 & 0.95 & 2.3 & 0.20 & 0.95 \\
\hline Vegetable planting share & -1.0 & -0.08 & 0.80 & -0.6 & -0.05 & 0.77 \\
\hline Farm size & 3.2 & 0.26 & $1.87^{\star}$ & 5.5 & 0.47 & $2.56^{\star}$ \\
\hline Family size & 0.0 & 0.00 & 0.83 & 3.0 & 0.26 & 0.82 \\
\hline Rotations per year & 4.4 & 0.40 & $1.41^{\star}$ & 1.1 & 0.1 & 1.34 \\
\hline Greenhouse type & 0.7 & 0.07 & 0.99 & 4.2 & 0.37 & 0.96 \\
\hline Beijing-Tianjin-Hebei region & 4.9 & 0.42 & 0.97 & 2.7 & 0.24 & 0.98 \\
\hline
\end{tabular}

Notes: NNM denotes nearest-neighbor matching. KBM denotes kernel-based matching. Asterisks ( ${ }^{\star \star \star}$, ${ }^{\star \star}$, and ${ }^{\star}$ ) denote significance at $1 \%, 5 \%$, and $10 \%$ levels, respectively.

Cite this article: Dong Y, Mu Y, and Abler D (2019). Do Farmer Professional Cooperatives Improve Technical Efficiency and Income? Evidence from Small Vegetable Farms in China. Journal of Agricultural and Applied Economics 51, 591-605. https:// doi.org/10.1017/aae.2019.22 